\title{
Effect of the 21-aminosteroid U-74006F on antigen-induced bronchoconstriction and bronchoalveolar eosinophilia in allergic sheep
}

\author{
K. Fujimoto, K. Kubo, K. Okada, T. Kobayashi, M. Sekiguchi, A. Sakai
}

Effect of the 21-aminosteroid U-74006F on antigen-induced bronchoconstriction and bronchoalveolar eosinophilia in allergic sheep. CERS Journals Ltd 1996.

ABSTRACT: U-74006F, a non-glucocorticoid 21-aminosteroid, has been developed as an inhibitor of iron-dependent lipid peroxidation. This class of compounds has been shown to prevent antigen-induced eosinophil accumulation in the lungs.

In this study, Ascaris-sensitive, "dual-respondent" sheep (showing both immediate (IAR) and late (LAR) asthmatic response) $(n=6)$ were used to assess the effect of U-74006F on antigen-induced bronchoconstriction and airway inflammation and reactivity $8 \mathrm{~h}$ after antigen challenge. Antigen provocation induced dual-phase bronchoconstriction, bronchoalveolar eosinophilia and airway hyperreactivity (AHR) to methacholine.

Throughout the experiment, intravenous administration of the drug significantly reduced the IAR and inhibited the LAR along with the inhibition of eosinophil influx, but did not inhibit the increase in airway reactivity observed $8 \mathrm{~h}$ after antigen challenge. Post-antigen challenge treatment with U-74006 from $3 \mathrm{~h}$ after antigen challenge also significantly reduced the LAR and bronchoalveolar eosinophilia, although the degree of inhibitory effect was milder. The development of the LAR appeared to be dependent on eosinophil recruitment into the lungs.

These findings suggest that lipid peroxidation is involved in antigen-induced bronchoconstriction and eosinophil recruitment into the lungs, and that the inhibitor $U$ $74006 \mathrm{~F}$ may be an effective drug for the treatment of bronchoconstriction and airway inflammation characterized by eosinophil infiltration in asthmatics.

Eur Respir J., 1996, 9, 2044-2049.
First Dept of Internal Medicine and Dept of Environmental Physiology, Shinshu University School of Medicine, Matsumoto, Japan.

Correspondence: K. Kubo

First Dept of Internal Medicine

Shinshu University School of Medicine 3-1-1, Asahi

Matsumoto

390 Japan

Keywords: Airway hyperreactivity

21-aminosteroid

Ascaris-sensitive allergic sheep model eosinophil

immediate asthmatic response

late asthmatic response

Received: November 281995

Accepted after revision June 151996
Airway inflammation, characterized by the infiltration of eosinophils, reversible bronchoconstriction, and airway hyperreactivity in response to nonspecific stimuli, underlies human bronchial asthma. Chronic airway inflammation is considered to be the most important pathogenetic factor in asthma, because the infiltrated inflammatory cells, eosinophils in particular, in the airway, produce various chemical substances that may contribute to the bronchoconstriction, excess secretion of mucus, epithelial damage, and nonspecific hyperreactivity that is characteristic of asthma [1]. Since corticosteroids prevent late-phase bronchoconstriction [2], allergen-induced airway hyperreactivity [3] and lung eosinophilia [4], many clinical investigators consider these drugs to be the most effective agents for the treatment of asthma [5]. However, the side-effects associated with systemically administered corticosteroids restrict their use. The development of nonglucocorticoid anti-inflammatory drugs that are as effective as corticosteroids is now anticipated.

It has recently been suggested that the airway inflammation in patients with asthma is associated with the increased generation of reactive oxygen species (ROS), which can influence airway cells and reproduce many of the pathophysiological changes associated with asthma by initiating lipid peroxidation [6]. The compound
U-74006F (21-[4-(2,6-di-1-pyrrolidinyl-4-pyrimidinyl)1-piperazinyl]-16-methyl-pregna-1,4,9(11)-triene-3,20dione, monomethane sulphonate) is one of an innovative series of non-glucocorticoid 21-aminosteroids that are potent inhibitors of iron-dependent lipid peroxidation without classical glucocorticoid actions [7-9]. This class of molecules have been shown to prevent the release of arachidonic acid metabolites and antigen-induced lung eosinophilia in sensitized animals [10-12]. In the present study, the effects of U-74006F administered intravenously on antigen-induced bronchoconstriction and airway inflammation and hyperreactivity to methacholine during the late asthmatic response (LAR) were examined in Ascaris-sensitive allergic sheep.

Material and methods

\section{Animal preparation}

Twelve sheep (mean weight $28.5 \mathrm{~kg}$ ), which were sensitive to Ascaris suum (A. suum) as demonstrated by a positive cutaneous reaction to a 1:1,000 dilution of crude A. suum extract (Greer Diagnostics, Lenoir, NC, USA) 
and showed dual-phase bronchoconstriction following $A$. suum inhalation prior to the research project (dual responders), were selected for this study. "Dual responders" were defined as animals exhibiting pulmonary resistance $(R \mathrm{~L})$ increased by more than $100 \%$ of baseline value immediately and $7 \mathrm{~h}$ after antigen inhalation, and $R \mathrm{~L}$ at 3 or $4 \mathrm{~h}$ was less than these two values. All animals had a silicon tube chronically placed in the vena cava via the right jugular vein for drug administration.

\section{Experimental design}

Protocol 1: effects of $U-74006 F$ treatment before antigen challenge $(n=6)$. Six sheep were randomly selected on three separate experimental occasions at timed intervals greater than two weeks. For the antigen-alone treatment, the sheep were challenged with A. suum antigen together with the infusion of placebo (solvent (CS4)), with no U-74006F treatment. For U-74006F-treatment, the sheep were challenged with A. suum antigen together with treatment with U-74006F (donated by J.M. McCall, Upjohn Laboratories, Kalamazoo, MI, USA) dissolved in the solvent (CS-4; $0.02 \mathrm{M}$ citric acid monohydrate, $0.0032 \mathrm{M}$ sodium citrate dihydrate, $0.077 \mathrm{M}$ $\mathrm{NaCl}, \mathrm{pH}$ 3.0). This class of compounds is highly lipophilic. When such compounds are added in organic solution to physiological buffers, they microprecipitate. Thus, in this study, the drug was prepared in a citric acid formulation, which is a superior delivery technique for the compounds.

The U-74006F, at a dose of $2 \mathrm{mg} \cdot \mathrm{kg}^{-1}$, was injected via the right jugular vein $30 \mathrm{~min}$ prior to antigen challenge. The preparation was also administered using an infusion pump, at a continuous dose of $0.5 \mathrm{mg} \cdot \mathrm{kg}^{-1} \cdot \mathrm{h}^{-1}$, throughout the experiment. On the controlled occasion, the sheep were given phosphate-buffered saline (PBS) by inhalation instead of $A$. suum, together with the administration of U-74006F. $R \mathrm{~L}$ measurements were obtained before drug administration was initiated; before antigen challenge; and at intervals immediately, 15 and $30 \mathrm{~min}$ and $1,2,3,4,5,6,6.5,7,7.5$ and $8 \mathrm{~h}$ after antigen challenge. After the $8 \mathrm{~h}$ measurement of $R \mathrm{~L}$, a dose-response curve to methacholine was obtained. Bronchoalveolar lavage (BAL) was performed after complete recovery from the methacholine challenge.

Protocol 2: effects of post-challenge treatment with $U$ $74006 \mathrm{~F}$ from $3 \mathrm{~h}$ after antigen challenge $(n=6)$. The 6 remaining sheep were treated with placebo or $\mathrm{U}-74006 \mathrm{~F}$ from $3 \mathrm{~h}$ after antigen challenge, and measurements of $R \mathrm{~L}$ were made in the same manner as in protocol 1 . After the $8 \mathrm{~h}$ measurements of $R \mathrm{~L}, \mathrm{BAL}$ was performed.

\section{Measurement of airway mechanics}

Unsedated sheep were restrained in a cart in the prone position with their heads immobilized. Topical anaesthesia of the nasal passages was applied with $4 \%$ lidocaine solution, and a balloon catheter was then advanced through one nostril into the lower oesophagus and positioned $5-10 \mathrm{~cm}$ from the gastro-oesophageal junction. Pleural pressure was estimated by filling the oesophageal balloon catheter with $2 \mathrm{~mL}$ of air. In this position, the end-expiratory pleural pressure was between -2 and -5 $\mathrm{cmH}_{2} \mathrm{O}$. Using a flexible fibreoptic bronchoscope as a guide, the animals were intubated with a cuffed endotracheal tube $(8.5 \mathrm{~mm}$ internal diameter (ID)) through the other nostril. Tracheal pressure was measured with a side-hole catheter ( $0.157 \mathrm{~cm}$ ID) advanced through and positioned distal to the tip of the endotracheal tube. Transpulmonary pressure $(P \mathrm{tp})$, the difference between tracheal and pleural pressure, was measured with a differential pressure transducer (Validyne Engineering Co., Northridge, CA, USA). Respiratory flow was measured with a Fleisch pneumotachograph (Chest Co., Tokyo, Japan) connected to the endotracheal tube. Respiratory volume was obtained by electrical integration from the flow signal. The signals for flow, transpulmonary pressure, and respiratory volume were recorded simultaneously on a multichannel recorder (San-ei Rectigraph-8K; NEC San-ei Instruments LD, Tokyo, Japan). No phase shift was observed between pressure and flow up to a frequency of $10 \mathrm{~Hz}$. RL was calculated by dividing the differential $P$ tp by flow at mid-tidal volume, and is expressed as the mean $R \mathrm{~L}$ calculated from 5 consecutive breaths.

\section{Antigen challenge}

The sheep were subjected to inhalation of A. Suum extract (100,000 protein nitrogen U.mL ${ }^{-1}$, Greer Diagnostics) with the use of a Harvard respirator (NSH34RH; Bodine Elect. Co., Chicago, IL, USA), at a tidal volume of 500 $\mathrm{mL}$ and at a rate of 20 breaths. $\mathrm{min}^{-1}$ over $20 \mathrm{~min}$. The aerosol was generated by an ultrasonic nebulizer (TUR3200; Nihon Koden, Tokyo). This nebulizer produced an aerosol with a mean mass aerodynamic diameter of 2-6 $\mu \mathrm{m}$.

\section{Measure of airway responsiveness}

In order to assess airway responsiveness to methacholine, culmulative dose-response curves obtained by subjecting the sheep to consecutive inhalations of methacholine in increasing concentrations $(0.16,0.31,0.63$, $1.25,2.5,5.0,10.0 \% \mathrm{w} / \mathrm{v}$ methacholine in normal saline). Normal saline (control) and each concentration of methacholine were inhaled for $1 \mathrm{~min}$. The nebulizer was operated by a respirator at a tidal volume of $500 \mathrm{~mL}$ and a rate of 20 breaths.min. The interval between the inhalations was 2 min. The measurements of $R \mathrm{~L}$ were repeated following the inhalation of normal saline, and methacholine solution of each increased concentration. Airway responsiveness was expressed as the cumulative methacholine provocative dose (units) required to increase $R \mathrm{~L}$ by 100 , and $200 \%$ over the postsaline value (PD100 and PD200), which was calculated from the methacholine doseresponse curve. One unit of methacholine was defined as a $1 \mathrm{~min}$ inhalation of $1.0 \%$ methacholine.

\section{Bronchoalveolar lavage (BAL)}

To obtain BAL fluid, a specially made flexible bronchofibrescope (Olympus Co., Tokyo, Japan) $90 \mathrm{~cm}$ long, with an outer diameter of $5.6 \mathrm{~mm}$, was wedged into a subsegmental bronchus. Two subsegmental bronchi in 
the bilateral middle lobes were selected at random in this experiment. Forty millilitres of normal saline, warmed to $37^{\circ} \mathrm{C}$, was injected via the bronchoscope and immediately aspirated into a collecting trap at $50 \mathrm{mmHg}$ negative pressure. This procedure was repeated three times. The fluid collected was immediately filtered through gauze. One small aliquot of this BAL fluid was used to count the total cells recovered under a microscope. To identify cell populations, another aliquot was spun in a cytometer (500 rpm for $5 \mathrm{~min}$ ) and stained with MayGrünwald-Giemsa. Excluding epithelial cells, 500 cells per slide were identified to establish the differential cell count (magnification $\times 100$, oil objective).

\section{Statistical analysis}

All data are presented as mean \pm SEM. Comparisons of $R \mathrm{~L}$ over time, in control, antigen alone, and U-74006F trials were made by two-way analysis of variance (ANOVA). Comparative tests at specific junctures were conducted with the paired t-test; comparisons of airway responsiveness and cell analysis were also made by paired ttest. If the p-value of the two-tailed test results was less than 0.05 , significance was accepted.

\section{Results}

Effects of U-74006F treatment before antigen challenge on antigen-induced bronchoconstrictive response

The inhalation of PBS did not cause any changes in $R \mathrm{~L}$ during the course of the experimental period. In placebo-treated sheep, antigen challenge caused characteristic early and late changes in $R$ L. After antigen

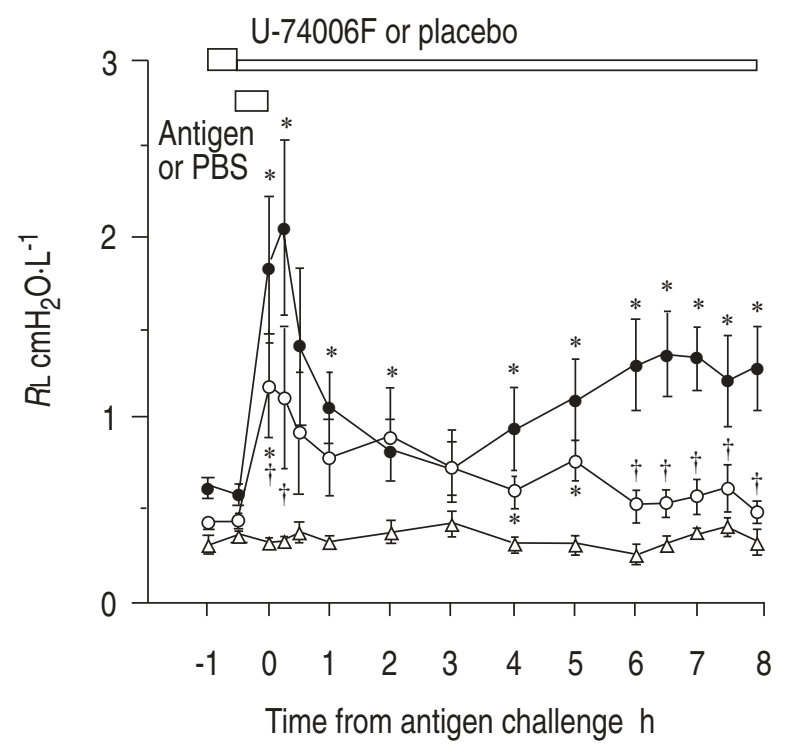

Fig. 1. - Effects of continuous intravenous administration of U$74006 \mathrm{~F}$ before antigen challenge on antigen-induced bronchoconstriction. U-74006F (-○-) $2 \mathrm{mg} \cdot \mathrm{kg}^{-1}$, or placebo $(-\bullet)$ was injected $30 \mathrm{~min}$ before antigen challenge and was then continously infused at a dose of $0.5 \mathrm{mg} \cdot \mathrm{kg}^{-1}$ throughout the experiment. As a control, sheep inhaled PBS instead of receiving antigen challenge with U-74006F treatment $(-\Delta-)$. Values are presented as mean \pm SEM for 6 sheep. PBS: phosphate-buffered saline $R \mathrm{~L}$ : pulmonary resistance. $*$ : $\mathrm{p}<0.05$ vs control; $\dagger: \mathrm{p}<0.05$ vs antigen alone. challenge, $R \mathrm{~L}$ significantly increased, peaking to $2.06 \pm$ $0.48 \mathrm{cmH}_{2} \mathrm{O} \cdot \mathrm{L}^{-1} \cdot \mathrm{s}$ from the baseline value of $0.58 \pm 0.06$ $\mathrm{cmH}_{2} \mathrm{O} \cdot \mathrm{L}^{-1} \cdot \mathrm{s} \quad(\mathrm{p}<0.01)$. $R \mathrm{~L}$ returned to baseline values within 2 or $3 \mathrm{~h}$, and then again showed a significant increase from $6 \mathrm{~h}$ onward, reaching a peak of $1.37 \pm 0.25$ $\mathrm{cmH}_{2} \mathrm{O} \cdot \mathrm{L}^{-1} \cdot \mathrm{s}$ in $6.5 \mathrm{~h}$. In U-74006F-treated sheep, the peak value of $R \mathrm{~L}$ during the early response was $1.19 \pm 0.28$ $\mathrm{cmH}_{2} \mathrm{O} \cdot \mathrm{L}^{-1} \cdot \mathrm{s}$. The $R \mathrm{~L}$ peak gradually decreased by 3 or $4 \mathrm{~h}$, with no residual tendency to increase again. The U74006F treatment significantly reduced both early $(\mathrm{p}<0.05)$ and late bronchoconstriction $(\mathrm{p}<0.01)$ (fig. 1). The inhibitory effect of the drug was marked in late bronchoconstriction.

Effect of U-74006F treatment before antigen challenge on airway responsiveness and inflammation during late response

The values both for PD100 $(5.7 \pm 1.7 \mathrm{U})$ and PD200 $(8.1 \pm 2.3 \mathrm{U})$ obtained $8 \mathrm{~h}$ after antigen challenge in the antigen only trials were significantly lower than those in control trials (PD100 10.5 \pm 1.9 U, PD200 18.2 $\pm 4.3 \mathrm{U}$ ) $(\mathrm{p}<0.01)$, which indicates that the antigen provocation induced airway hyperresponsiveness (AHR) to methacholine. In U-74006F-treated sheep, however, the values

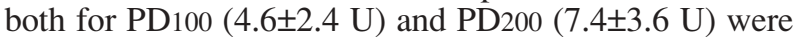
almost the same as those in the antigen-only trials. U$74006 \mathrm{~F}$ did not reduce the AHR $8 \mathrm{~h}$ after antigen challenge (fig. 2).

Antigen challenge induced significant increases in the number of total cells recovered and both in relative and absolute numbers of lymphocytes, neutrophils and eosinophils recovered in BAL fluid obtained $8 \mathrm{~h}$ after challenge (table 1). U-74006F treatment did not significantly affect the increases in the number of total

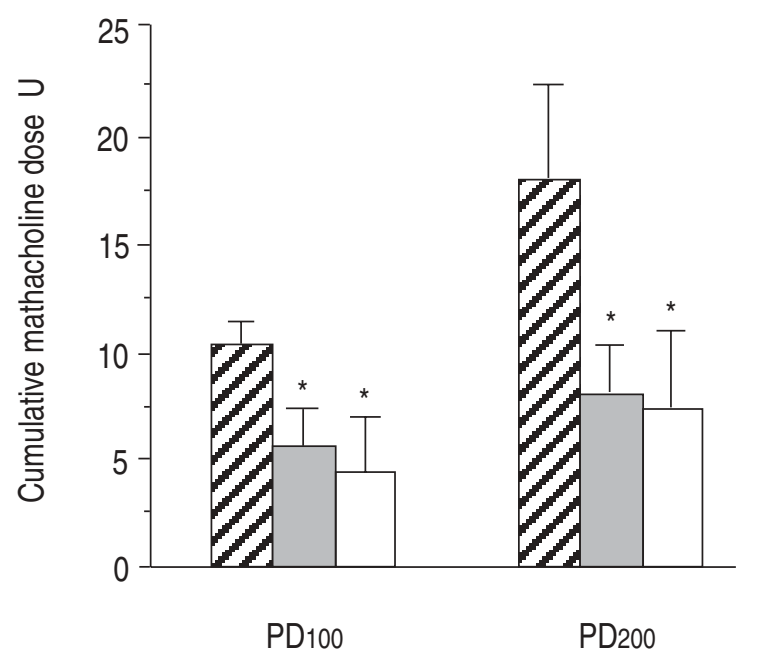

Fig. 2. - Effects of continuous intravenous administration of U$74006 \mathrm{~F}$ before antigen challenge on airway responsiveness to methacholine measured $8 \mathrm{~h}$ after challenge. Values are presented as mean \pm SEM for six sheep. PD100, PD200; cumulative methacholine provocative dose required to increase pulmonary resistance $(R \mathrm{~L})$ by 100 and $200 \%$, respectively, over the postsaline value. PD100 and PD200 were obtained by interpolation from the individual dose-response curves. One unit (U) of methacholine was defined as the amount received in $1 \mathrm{~min}$ inhalation of $1.0 \%$ methacholine. ${ }^{*}: \mathrm{p}<0.05 \mathrm{vs}$ control. $^{-\cdots}$ : control; : antigen alone; : U-74006F prior to antigen. 
Table 1. - Effects of continuous intraveous administration of U-74006F before antigen challenge on cell analysis in BALF obtained $8 \mathrm{~h}$ after challenge

\begin{tabular}{cccc}
\hline & Control & Antigen alone & U-74006F \\
\hline Total cells $\times 10^{5} \cdot \mathrm{mL}^{-1}$ & $6.8 \pm 0.8$ & $17.3 \pm 3.4^{*}$ & $14.2 \pm 4.0^{*}$ \\
Macrophages \% & $92 \pm 1$ & $62 \pm 5^{*}$ & $67 \pm 10$ \\
$\times 10^{5} \cdot \mathrm{mL}^{-1}$ & $6.3 \pm 0.8$ & $10.5 \pm 2.0$ & $9.0 \pm 2.6$ \\
Lymphocytes \% & $4.1 \pm 0.5$ & $13.0 \pm 1.7^{*}$ & $17.2 \pm 5.1$ \\
$\times 10^{5} \cdot \mathrm{mL}^{-1}$ & $0.27 \pm 0.05$ & $2.18 \pm 0.40^{*}$ & $2.25 \pm 0.81$ \\
Neutrophils \% & $3.7 \pm 0.7$ & $9.0 \pm 2.8^{*}$ & $13.1 \pm 7.3$ \\
$\times 10^{5} \cdot \mathrm{mL}^{-1}$ & $0.24 \pm 0.05$ & $1.55 \pm 0.54^{*}$ & $2.76 \pm 1.79$ \\
Eosinophils \% & $0.1 \pm 0.0$ & $15.9 \pm 5.2^{*}$ & $2.3 \pm 1.2^{*+}$ \\
$\times 10^{5} \cdot \mathrm{mL}^{-1}$ & $0.01 \pm 0.00$ & $3.02 \pm 1.40^{*}$ & $0.23 \pm 0.11^{*+}$ \\
& & &
\end{tabular}

Values are presented as mean \pm SEM for six sheep. BALF: bronchoalveolar lavage fluid. *: $\mathrm{p}<0.05$ vs control; +: $\mathrm{p}<0.05$ vs antigen alone.

cells recovered or the increased lymphocytes and neutrophils recovered. However, U-74006F significantly reduced both relative and absolute numbers of eosinophils recovered.

\section{Effects of post-antigen challenge treatment with $U-74006 F$ on the LAR and airway inflammation}

Antigen challenge induced a 3.5 fold increase in $R \mathrm{~L}$ immediately after the provocation and a threefold increase in $R \mathrm{~L}$ during the LAR and bronchoalveolar eosinophilia, similar to that for antigen alone as measured in protocol 1. Post-treatment of U-74006F from $3 \mathrm{~h}$ after antigen challenge significantly reduced the late-phase bronchoconstriction (fig. 3) and the increase in relative number of eosinophils recovered (table 2), and resulted in $27 \%$ inhibition of the late-phase increase in $R \mathrm{~L}$ and $50 \%$ inhibition of the relative numbers of eosinophils recovered.

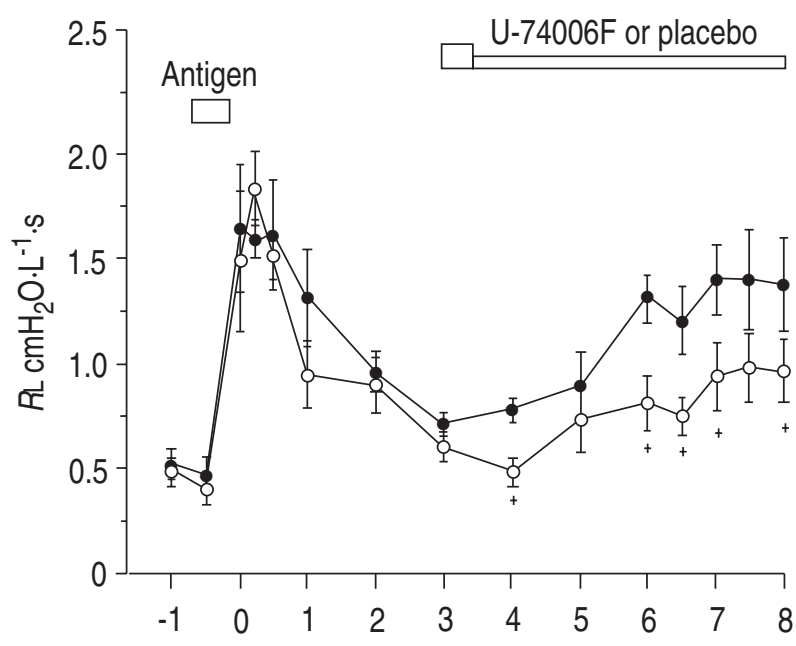

Time from antigen challenge $h$

Fig. 3. - Effects of post-treatment of U-74006F from $3 \mathrm{~h}$ after antigen challenge on LAR. U-74006F (-○) $2 \mathrm{mg} \cdot \mathrm{kg}^{-1}$, or placebo (—) was injected $3 \mathrm{~h}$ after antigen challenge and was then continuously infused at a dose of $0.5 \mathrm{mg} \cdot \mathrm{kg}^{-1}$ until the end of the experiment. Values are presented as mean \pm SEM for six sheep. LAR: late asthmatic response; $R \mathrm{~L}$ : pulmonary resistance. $+: \mathrm{p}<0.05 \mathrm{vs}$ antigen alone.
Table 2. - Effects of post-antigen challenge treatment with U-74006F on cell analysis in BALF obtained $8 \mathrm{~h}$ after challenge

\begin{tabular}{ccc}
\hline & Antigen alone & $\mathrm{U}-74006 \mathrm{~F}$ \\
\hline Total cells $\times 10^{5} \cdot \mathrm{mL}^{-1}$ & $15.5 \pm 3.6$ & $10.2 \pm 1.3$ \\
Macrophages \% & $76 \pm 5$ & $80 \pm 7$ \\
$\times 10^{5} \cdot \mathrm{mL}^{-1}$ & $10.9 \pm 1.7$ & $8.2 \pm 1.4$ \\
Lymphocytes \% & $8.1 \pm 1.5$ & $5.8 \pm 1.6$ \\
$\times 10^{5} \cdot \mathrm{mL}^{-1}$ & $1.3 \pm 0.4$ & $0.57 \pm 0.17$ \\
Neutrophils $\%$ & $5.2 \pm 0.5$ & $8.6 \pm 4.8$ \\
$\times 10^{5} \cdot \mathrm{mL}^{-1}$ & $0.84 \pm 0.24$ & $0.87 \pm 0.48$ \\
Eosinophils \% & $11.5 \pm 3.9$ & $5.8 \pm 1.6^{+}$ \\
$\times 10^{5} \cdot \mathrm{mL}^{-1}$ & $2.43 \pm 1.40$ & $0.56 \pm 0.15$ \\
\hline
\end{tabular}

Values are presented as mean \pm sem for six sheep. BALF: bronchoalveolar lavage fluid. ${ }^{+}: \mathrm{p}<0.05$ vs antigen alone.

The degree of these inhibitory effects was mild when compared with those in sheep continuously treated with the drug before antigen challenge $(64 \%$ inhibition of the LAR and $86 \%$ inhibition of relative numbers of eosinophils recovered).

\section{Discussion}

$\mathrm{U}-74006 \mathrm{~F}$ is one of the non-glucocorticoid 21-aminosteroids, which has been developed as an inhibitor of iron-dependent lipid peroxidation (LP) and selected for clinical development as an administered acute neuroprotective agent. The drug is currently the focus of phase III clinical trials for head and spinal cord injuries, ischaemic stroke, and aneurysmal subarachnoid hemorrhage; and the trials have demonstrated that the drug is safe and effective for the treatment of these disorders [9]. This class of molecule is devoid both of glucocorticoid and mineralcorticoid activity [8]. These agents exert antiLP action through co-operative mechanisms: a radical scavenging action (i.e. chemical antioxidant effect) and a physicochemical interaction with the cell membrane that serves to decrease membrane fluidity (i.e. membrane stabilization). The 21-aminosteroids have been shown to prevent the release of arachidonic acid, the influx of calcium into cells, the appearance of membrane lipid fragments, and the destruction of membrane-localized enzymatic activity [7-9].

They have also been shown to prevent antigen-induced lung eosinophilia in sensitized animals [10-12]. The 21aminosteroid U-75412E is a very close structural analogue of U-74006F and has been shown to prevent not only the influx of eosinophils into the bronchial lumen, as measured in BAL fluid, but also the infiltration of eosinophils into peribronchial connective tissue and mucosal epithelium in ovalbumin-sensitized Brown Norway rats [12]. In the present study, the continuous intravenous administration of $\mathrm{U}-74006 \mathrm{~F}$ before antigen challenge significantly inhibited eosinophil influx into the airway, reduced late-phase bronchoconstriction, and resulted in $86 \%$ inhibition of bronchoalveolar eosinophilia and 64\% inhibition of the late-phase increase in $R \mathrm{~L}$. Post-treatment of the drug from $3 \mathrm{~h}$ after challenge also reduced the bronchoalveolar eosinophilia and the LAR, and resulted in $50 \%$ inhibition of bronchoalveolar eosinophilia and $27 \%$ inhibition of the late-phase increase in $R \mathrm{~L}$. The 
inhibitory effects of post-treatment were milder when compared with those in sheep treated before antigen challenge, and the inhibitory effect on the LAR appeared to be dependent on eosinophil recruitment into the airway.

It has been suggested that eosinophils are the most important effector cells in bronchial asthma, and a close association has been shown between eosinophil infiltration and late-phase bronchoconstriction [1, 13-15]. DeMonchy et al. [13] have demonstrated increases in BAL eosinophils and eosinophil cationic protein after allergen challenge in late asthmatic responders, but not in single early asthmatic responders; the lung eosinophilia was correlated not only with the magnitude of the LAR but also with the baseline level of airway responsiveness $[14,15]$. Eosinophils can produce a large amount of sulphidopeptide leukotrienes, which it has been suggested are the major constrictive substances responsible for the induction of the $\operatorname{LAR}[16,17]$. These findings suggest that the most plausible mechanism involved in the inhibition of the LAR may act by inhibiting eosinophil accumulation in the airway.

The involvement of arachidonic acid metabolites in antigen-induced bronchoconstriction and eosinophil accumulation in the lungs is well-established [16-20]. Therefore, it may be that the inhibition of release of eosinophil chemotaxis initiated by lipid peroxidation during the LAR results in reduced bronchoalveolar eosinophilia and the LAR, because the drug has been demonstrated to block arachidonic acid release [8, 9]. However, in light of the present findings that post-treatment with U$74006 \mathrm{~F}$ also reduced eosinophil recruitment into the airway, another mechanism by which the drug directly inhibited eosinophil migration, e.g. a membrane stabilizing action of the drug, may also be involved. U-74006F also significantly reduced early-phase bronchoconstriction. Not only histamine, but also arachidonic acid metabolites, such as thromboxane $\mathrm{A} 2\left(\mathrm{Tx}_{2}\right)$, prostaglandin $\mathrm{D}_{2}\left(\mathrm{PGD}_{2}\right)$, and leukotriene $\mathrm{D}_{4}\left(\mathrm{LTD}_{4}\right)$ participate in the immediate bronchoconstriction $[18,21,22]$. It is, therefore, reasonable to conclude that the drug directly inhibited the production of arachidonic acid metabolites, which resulted in a reduction of the early-phase response.

Many authors have reported the implication of ROS and the imbalance between oxidant and antioxidant defence systems in the pathogenesis of asthma [6, 23]. Antigens can induce the generation of ROS, especially associated with airway inflammation, which can produce arachidonic acid metabolites through the initiation of lipid peroxidation $[24,25]$. Therefore, as a possible mechanism, it may be that the inhibitory effects of the drug on the LAR and eosinophil recruitment was due to the lessening of the lipid mediators through the inhibition of lipid peroxidation initiated by ROS. However, there are few reports concerning ROS implicated in the development of the LAR and lung eosinophilia [26]. Adding to the antioxidant action, U-74006F also has a membrane stabilizing action as an anti-LP agent [9]. It is difficult to distinguish which is the main action. We speculate that both the antioxidant and membrane stabilizing actions of the drug contributed to the inhibition of antigen-induced LAR and lung eosinophilia in the present study.

The bronchial biopsy specimens of asthmatics show striking inflammatory changes and ultrastructural and histochemical signs of eosinophil activation [1]. It is thought that cytotoxic substances released from activated eosnophils may lead to epithelial damage resulting in airway hyperreactivity [14, 27]. However, in the present study, U-74006F did not affect the increased airway reactivity to methacholine as measured $8 \mathrm{~h}$ after antigen challenge, although the eosinophil influx was inhibited. The baseline airway tones at the time airway reactivity was measured in the antigen-challenged group were higher than those before the measurement of airway reactivity in the drug-treated group, a factor which could have affected the evaluation of the reactivity. However, the reactivity to methacholine in the drug-treated group was significantly higher than that in controls, although there was no difference in the baseline tone. These findings indicate that the drug did not inhibit the increased airway reactivity to methacholine $8 \mathrm{~h}$ after antigen challenge.

It has been suggested that the mechanism leading to the cholinergic AHR during the LAR differs from that seen after (i.e. $24 \mathrm{~h}$ ) the LAR $[16,28]$. A $\mathrm{LTD}_{4}$ receptor antagonist prevented the LAR but did not abrogate the AHR during the LAR [16]. Another leukotriene antagonist was found to block both the LAR and AHR that occurred $24 \mathrm{~h}$ after challenge in allergic sheep [29]. A close association has been demonstrated between lung eosinophilia and the AHR seen after the LAR [16]. However, we previously observed that an influx of neutrophils, and neutrophil elastase, is involved in the development of AHR during the LAR in allergic sheep [30]. Thus, our results indicate that the eosinophil influx is not a major contributor to the development of AHR observed $8 \mathrm{~h}$ after antigen challenge in this allergic sheep model.

In conclusion, U-74006F inhibited late phase bronchoconstriction and eosinophil influx in the airway, and reduced early-phase bronchoconstriction. Post-antigen challenge treatment with the drug also significantly reduced the late asthmatic response and eosinophil influx. These findings suggest that lipid peroxidation is involved in antigen-induced bronchoconstriction and eosinophil recruitment into the lungs, and that the inhibitor U-74006F could be an effective drug for the treatment of bronchoconstriction and airway inflammation characterized by eosinophil infiltration in asthmatics.

Acknowledgment: The authors thank J.M. McCall (Upjohn Laboratories, Kalamazoo, MI, USA) for providing U-74006F, and for support during this study.

\section{References}

1. Djukanovic R, Roche WR, Wilson JW, et al. Mucosal inflammation in asthma. Am Rev Respir Dis 1990; 142: 434-457.

2. Booij-Noord H, Orie NGM, de Vries K. Immediate and late bronchial obstructive reactions to inhalation of house dust and protective effects of disodium cromoglycate and prednisolone. J Allergy Clin Immunol 1971; 48: 344-354.

3. Barnes PJ. Effect of corticosteroids on airway hyperresponsiveness. Am Rev Respir Dis 1990; 141: S70-S76.

4. Horn BR, Robin ED, Theodore J, Van Kessel A. Total eosinophil counts in the management of bronchial asthma. N Engl J Med 1975; 292: 1152-1155. 
5. National Heart, Lung and Blood Institute, National Institute of Health, USA. International consensus report on diagnosis and management of asthma, US Department of Health and Human Services, Public Health Service, A.L. Clin Exp Allergy 1992; 22 (Suppl. 1): 1-72.

6. Barnes PJ. Reactive oxygen species and airway inflammation. Free Rad Biol Med 1990; 9: 235-243.

7. Braughler JM, Pregenzer JF, Chase RL, Duncan LA, Jacobsen EJ, McCall JM. Novel 21-aminosteroids as potent inhibitors of iron-dependent lipid peroxidation. $J$ Biol Chem 1987; 262: 10438-10440.

8. Braughler JM, Pregenzer JF, Chase RL. A new 21-aminosteroid antioxidant lacking glucocorticoid activity stimulates ACTH secretion and blocks arachidonic release from mouse pituitary tumor (AtT-20) cells. J Pharmacol Exp Ther 1988; 244: 423-427.

9. Hall ED, McCall JM, Means ED. Therapeutic potential of the lazaroids (21-aminosteroids) in acute central nervous system trauma, ischemia and subarachnoid hemorrhage. Adv Pharmacol 1994; 28: 221-268.

10. Richards IM, Shields SK, Griffin RL, Dunn CJ. A novel model of antigen-induced lung eosinophilia in BrownNorway rats: effects of methylprednisolone. Eur $J$ Pharmacol 1990; 183: 1191-1192.

11. Richards IM, Shields SK, Bienkowski M, Dunn CJ, Jacobsen EJ. Novel inhibitors of pulmonary eosinophil accumulation. Agents Actions 1991; 34: 359-368.

12. Richards IM, Shields SK, Griffin RL, Fidler SF, Dunn CJ. Novel steroid-based inhibitors of lung inflammation. Clin Exp Allergy 1992; 22: 432-439.

13. De Monchy JGR, Kauffinan HF, Venge P, et al. Bronchoalveolar eosinophilia during allergen-induced late asthmatic reactions. Am Rev Respir Dis 1985; 131: 373-376.

14. Durham SR, Kay AB. Eosinophils, bronchial hyperreactivity and late-phase asthmatic reactions. Clin Allergy 1985; 15: 411-418.

15. Wardlaw AJ, Dunnette S, Gleich GJ, Collins JV, Kay $\mathrm{AB}$. Eosinophils and mast cells in bronchoalveolar lavage in subjects with mild asthma: relationship to bronchia hyperreactivity. Am Rev Respir Dis 1988; 137: 62-69.

16. Soler M, Sielczak M, Abraharn WM. Separation of late bronchial responses from airway hyperresponsiveness in allergic sheep. J Appl Physiol 1991; 70: 617-623.

17. Friedman BS, Bel EH, Buntinx A, et al. Oral leukotriene inhibitor (MK-886) blocks allergen-induced airway responses. Am Rev Respir Dis 1993; 147: 839-844.

18. Abraham WM. The importance of lipoxygenase products of arachidonic acid in allergen-induced late responses. Am Rev Respir Dis 1987; 135: S49-S53.
19. Coyle AJ, Urwin SC, Page CP, Touvay C, Villain B, Braquet $\mathrm{P}$. The effect of the selective PAF antagonist BN 52021 on PAF- and antigen-induced bronchial hyperreactivity and eosinophil accumulation. Eur J Pharmacol 1988; 148: 51-58.

20. Chabot-Fletcher MC, Underwood DC, Breton JJ, et al. Pharmacological characterization of SB 202235, a potent and selective 5-lipoxygenase inhibitor: effects in models of allergic asthma. J Pharmacol Exp Ther 1955; 273: 1147-1155.

21. Matsumoto T, Ashida Y, Tsukuda R. Pharmacological modulation of immediate and late airway response and leukocyte infiltration in guinea-pig. $J$ Pharmacol Exp Ther 1994; 269: 1236-1244.

22. Abraham WM. The role of leukotrienes in allergeninduced late responses in allergic sheep. Ann NY Acad Sci 1988; 524: 260-270.

23. Owen S, Pearson D, O'Driscoll R, Woodcock A. Evidence of free radical activity in asthma. N Engl J Med 1991; 325: 586-587.

24. Abraham WM. The interaction among granulocyte lipid mediators and the generation of oxygen radicals in antigeninduced airway hyperresponsiveness. Adv Prostaglandin Thromboxane Leukotriene Res 1994; 22: 131-140.

25. Ikuta N, Sugiyama S, Takagi K, Satake T, Ozawa T. Implication of oxygen radicals on airway hyperresponsiveness after ovalbumin challenge in guinea-pigs. Am Rev Respir Dis 1992; 145: 561-565.

26. Matsuyama T, Ihaku D, Tanimukai T, Uyarna O, Kitada O. Superoxide dismutase suppressed asthmatic response with inhibition of manganese superoxide induction in rat lung. Nippon Kyobu Shikkan Gakkai Zasshi 1993; 31: 139-145.

27. Reid LM, Gleich GJ, Hogg J, Kleinerman J, Laitinen LA. Pathology. In: Holgate ST, ed. The Role of Inflammatory Processes in Airway Hyperresponsiveness. Oxford, Blackwell Scientific Publications, 1989; pp. 36-79.

28. Durham SR, Graneek BJ, Hawkins R, Taylor AJN. The temporal relationship between increases in airway responsiveness to histamine and late asthmatic responses induced by occupational agents. J Allergy Clin Immunol 1987; 79: 398-406.

29. Lanes S, Stevenson JS, Codias E, et al. Indomethacin and FPL-57231 inhibit antigen-induced airway hyperresponsiveness in sheep. $J$ Appl Physiol 1986; 61: 864872.

30. Fujimoto K, Kubo K, Shinozaki S, et al. Neutrophil elastase inhibitor reduces asthmatic responses in allergic sheep. Respir Physiol 1995; 100: 91-100. 